\title{
Comentario
}

\section{Politicas de información: Politicas de Servicios Bibliotecarios y de Información}

\begin{abstract}
A hablar de políticas de información, en particular en biblio$\mathrm{A}_{\text {tecas, lleva a considerar un conjunto de actividades bibliote- }}$ carias que influyen, o no, en la prestación de servicios bibliotecarios y de información en el más amplio sentido de la palabra.

Esta definición simplemente deja de lado todas aquellas construcciones teóricas y metodológicas que o bien llegan a apuntalar o a recrear la labor de investigación que gira alrededor de la temática.

La forma de acercarse a la temática es muy amplia y ha sido abordada desde múltiples aristas, lo que ha implicado conocer la complejidad en la que se encuentra inmersa y tratar de reducirla para conocer los actores, los entornos y los paradigmas que están implicados.

No obstante lo anterior esta complejidad se puede reducir al tratar los aspectos inherentes de la organización bibliotecaria, como son:
\end{abstract}

1) los Recursos Humanos; 2. las Colecciones; 3. la Organización Documental; 4. el Desarrollo de Servicios Bibliotecarios y de Información; 5. la Cooperación Bibliotecaria, y 6. el Fortalecimiento de la Infraestructura en general.

La tecnología de información y de la comunicación, la Internet y la emergente globalización aunadas a las tendencias de la sociedad de la información, y la también denominada sociedad del conocimientos y del saber; sin embargo, han transformado la manera de brindar dichos servicios. 
El énfasis puesto en estos servicios paulatinamente ha sido trasladado hacia la disponibilidad y el suministro de información y ha dejado de lado el modelo tradicional, basado en ser propietario de voluminosas colecciones de una gran variedad temática.

Bajo esta óptica las unidades de información y las bibliotecas se convierten en un medio para conseguir el acceso a la información y a los documentos.

La función del bibliotecario en este sentido cambia al dejar de ser recopilador de información en general y convertirse en mediador, aquél que le abre a sus usuarios las puertas de las posibilidades al amplio acceso del mundo de la información.

Este cambio de escenario llevaría a la reflexión de la tercera ley de Ranganathan: a cada lector su libro, que está muy relacionada con la filosofía del acceso universal a la información.

Ahora bien, cada biblioteca o unidad de información traza y fija los objetivos para que se cumpla dicha ley de acuerdo a la misión y la visión marcada tradicionalmente a través de sus políticas de servicios bibliotecarios.

El acceso que se busca es a los inmuebles y a los servicios que tienen que ver con los contenidos que presta y alberga la biblioteca.

Esto se puede sintetizar, ante todo, como:

1. un proceso de aproximación a la información documental; la identificación de los documentos, sea a través de catálogos, repertorios bibliográficos o bases de datos, entre otros.

2. la disponibilidad de la información; el documento se encuentra físicamente al alcance del usuario, o lo está por medio de los servicios de los bibliotecarios que ofrecen las unidades de información.

3. el uso de la información; visto como acceso cognitivo, donde el idioma no es una barrera para su uso y apropiación. ${ }^{1}$

Ante la incursión de las tecnologías de información y comunicación (TIC) en las unidades de información, habrá que

1 G. A. Torres Vargas, El concepto de biblioteca virtual y su relación con el acceso universal a los documentos, Tesis doctoral, Universidad complutense de Madrid, Facultad de Ciencias de la Información, 1999. 
revisar las políticas, los reglamentos y los procedimientos con el fin de brindar excelentes servicios en toda la extensión de la palabra.

La tecnología en este caso será uno de los aliados que contribuirán a una mejor accesibilidad no sólo a las voluminosas colecciones que alberga sino también a los recursos y fuentes de información adquiridas.

Debe hacerse notar que en ocasiones se piensa que el acceso a la información, también denominado servicios de acceso, no es algo totalmente novedoso; sin embargo sí ha ido cambiando de nombre, así como también las actividades que desarrolla, debido en buena parte al contexto y al entorno digital.

A grosso modo los servicios de acceso comprenden el hecho de brindar información a los usuarios de la biblioteca. Para ello, el departamento de procesos técnicos organiza los documentos de cualquier índole, sean estos bibliográficos o estén en cualquier otro formato, y archivísticos, tanto impresos como electrónicos, para lo cual utilizará las técnicas adecuadas para su sistematización y pronta recuperación.

En segundo lugar el personal de la biblioteca juega aquí un papel clave, ya que orienta y apoya a los usuarios en la recuperación de la información. Este proceso finaliza cuando el usuario obtiene el documento solicitado, gracias a las fuentes que le fueron facilitadas así como al apoyo de todos los instrumentos utilizados para obtener el acceso a la información requerida.

Aun cuando algunos servicios de acceso son conocidos por los usuarios, como la circulación, ordenamiento y colocación en la estantería; o la reserva, el préstamo interbibliotecario, el almacenamiento remoto y la gestión de espacio de estudios, en el contexto electrónico se pueden mencionar otros como la digitalización, el apoyo a la educación a distancia y el suministro de documentos en texto completo y la recuperación electrónica por medio de la Internet.

Cabe mencionar que otros servicios no menos importantes siguen vigentes como son el servicio de hemeroteca, el fotocopiado, la preservación y los servicios de audiovisuales.

El cambio de contexto ha hecho que los servicios de acceso se hayan ido ampliando y han hecho surgir la pregunta de ¿cuáles de estos servicios deben ser gratuitos y cuáles conllevan un costo para el usuario? 
En este contexto habrá que evaluar las políticas de servicios bibliotecarios y de información existentes para verificar su pertinencia, y en caso de no estar de acuerdo con los requerimientos de la comunidad a la que brinda sus servicios, tendrá que iniciar un proceso de evaluación integral de los mismos tomando como parámetro el contexto, el momento histórico por el que atraviesa la institución (la misión y la visión) y los factores exógenos y endógenos. Estos factores de una u otra manera intervienen en la toma de decisiones y determinan las estrategias que habrán de seguir modificando o transformando las políticas de los servicios bibliotecarios para ponerlas a la vanguardia.

Finalmente, los estudios sobre las políticas de los servicios bibliotecarios y de información están girando siempre alrededor del acceso a la información, la accesibilidad, el uso o usabilidad y los servicios de acceso.

Egbert J. Sánchez Vanderkast 